\title{
Dermatoglyphics research for COVID-19
}

\section{Letter to editor}

In the interest of scientific research, I ask the following questions:

1. Is there a correlation between fingerprint patterns and individuals who test positive for COVID-19 who are asymptomatic?

2. Is there a correlation between fingerprint patterns and individuals who recover from COVID-19 more quickly than others?

If we know the answer to the aforementioned questions, we can then ask the question: What is it in their genetic information that provides some resistance to the infection? Knowing this will enable us to determine a way that people can be reincluded into a healthy work force. Medical science is aware that dermatoglyphics is a marker for genetic disorders. We should therefore explore the genetic make-up of individuals from an additional perspective. In other words, we must discover the genetic element(s) that helps to reduce the COVID-19 infection. The dermal ridge arrangements are a reflection of our genetic profile. Therefore, it would be a good idea to look at dermatoglyphics to approach this issue as well. This is safe research in that using dermatoglyphics would be unintrusive for individuals. In addition, it would not be necessary to fingerprint individuals who already have a record on file. They need only to release their fingerprint record for the study. Once a correlation is known between fingerprint classifications and those who are asymptomatic, we can examine the genetic structure of those in coincidence to discover the genetic element(s) that can be transferred or created for other individuals.

I have noted that the National Crime Information Center Fingerprint Classification (NCIC FPC) provides 114 different fingerprint classifications which can appear on any of the ten digits; a total of $3.707221314118566 \mathrm{e}+20$ combinations; which is three hundred seventy quintillion seven hundred twenty-two quadrillion one hundred thirty-one trillion four hundred eleven billion eight hundred fifty-six million six hundred thousand.

Under this structure, we can use the following statistics to discover a departure in pattern consistency:

The frequency of the NCIC FPC for 17,951,192 individuals from the male population, at

http://www.dermatoglyphics.com/mfre/
Volume 5 Issue 2 - 2020

\section{Andres J Washington}

Fingerprint Geometric Analysis, USA

Correspondence: Andres JWashington, Fingerprint Geometric Analysis, Post Office Box 165 Bronx, New York 10451-0165, USA, Tel 9149603526, Email director@dermatoglyphics.com

Received: May 12, 2020 | Published: May 29, 2020

The frequency of the NCIC FPC for 4,313,521 individuals from the female population, at

http://www.dermatoglyphics.com/femfre/

If for example, ten percent of the people who test positive for COVID-19 are asymptomatic, we should look at fingerprint classifications that are near the ten percent margin for a given population. CNN recently reported that according to the CDC $35 \%$ of the population is asymptomatic. The whorl pattern is $35 \%$ of the total of all fingerprint patterns. If $35 \%$ of the population is asymptomatic, my request is to look in the direction of individuals with the whorl type pattern; there are four different whorl type classifications. And they are: Plain Whorl, Central Pocket Loop Type Whorl, Double Loop Whorl and the Accidental Whorl. All of which are subdivided into Inner, Meeting and Outer tracings.

\section{Whorl frequencies}

Distribution of NCIC FPC Whorl Patterns Including 17,951,192 Males

http://www.dermatoglyphics.com/malewhorls.pdf

Distribution of NCIC FPC Whorl Patterns Including 4,313,521 Females

http://www.dermatoglyphics.com/femalewhorls.htm 